\title{
New Sound Absorbing Materials Obtained from Waste Rigid Polyurethane Foam
}

\author{
ANCUȚA-ELENA TIUC ${ }^{1}$, OVIDIU NEMEȘ ${ }^{*}$, HORAȚIU VERMEŞAN ${ }^{*}$, DANIELA-ROXANA TĂMAȘ-GAVREA ${ }^{2}$, \\ OVIDIU VASILE ${ }^{3}$ \\ ${ }^{1}$ Technical University of Cluj-Napoca, Faculty of Materials and Environmental Engineering, 103-105 Muncii Blvd., 400641, \\ Cluj-Napoca, Romania \\ ${ }^{2}$ Technical University of Cluj-Napoca, Faculty of Civil Engineering, 15 C-tin Daicoviciu Str., 40020, Cluj-Napoca, Romania \\ ${ }^{3}$ University "Politehnica" of Bucharest, Department of Mechanics, 313 Splaiul Independente, 060042 Bucharest, Romania
}

Polyurethane foam wastes is one of the environmental problems for which are not still the efficient solutions of valorization. This paper presents the possibility of recovering polyurethane foam waste by obtaining some new materials with sound absorption properties. The polyurethane foam wastes were ground and mixed, in proportion of 0, 3, 5, 7 and $12 \mathrm{wt} \%$, with bicomponent polyurethane foam as a binder, resulting 5 new materials. The soundabsorbing properties of the new materials have been determined and it can be observed that the sound-absorbing properties of rigid polyurethane foam with closed pores can be improved by adding polyurethane foam waste to its structure. In addition, the mechanical properties and thermal conductivity of the new materials were studied.

Keywords: waste polyurethane foam, acoustic materials

The circular economy represents an organized effort within society in order to find solutions to the current environmental problems that are generated by the development of the society. Sustainable development and the respect for the environment are social values that have to be encouraged through the implementation of strategies that valorize the waste products generated in industrial processes and transform them into resources [1].

Polyurethane products are present in many industrial goods either in flexible or rigid foams, depending on their mechanical performance and cross-link densities [2]. Rigid polyurethane foams (PURs) are widely used in building insulation, domestic appliances, the automotive industry and as an insulation and lining material for refrigerators and freezers $[3,4]$.

The presence of polyurethane foam in municipal waste is related to the end of product life, but it may also be derived as scrap from the manufacturing process which can account for approximately 10-15\% of produced foam [5]. The recycling of PUR foam wastes, meets a serious difficulty arising from their considerably low density of 10-100 $\mathrm{kg} / \mathrm{m}^{3}$. Thus, the volume reduction is a crucial issue in the management of waste PUR foam [6].

It is therefore necessary to establish recycling procedures or ways of reusing industrial waste in order to minimize its environmental impact. The major recycling and recovery methods for polyurethanes [7] used up to date are mechanical recycling, advanced chemical and thermo-chemical recycling, energy recovery and product recycling respectively. Less efficient are the traditional recycling methods such as landfill storage and incineration which lead to land occupation, resource consumption, toxic gas emission, and environmental pollution [8]. Effectively disposing waste polyurethane foam plays an important role in protecting environment and recycling resources [9].

The thermal degradation of polyurethane foams leads to a significant amount of hazardous and harmful compounds that can arise during the decomposition process. The direct utilization of PU foam for waste-to-energy applications is not advised due to the possibility of the degradation of this, with the formation of hazardous chemical compounds. The chemical pretreatment or mixing with other waste materials is recommended to achieve safe and sustainable performance [2, 10-13].

The use of polymeric waste in the manufacture of mortar and concrete implies an important environmental benefit [14]. Specifically, the incorporation of rigid polyurethane waste in the design of lightweight cement mortars, and their manufacture for use in construction, has been widely researched, both in reference to the characterization of their physical properties and to the study of their mechanical behavior [15].

Rigid PUR foams are an ideal solution to lightweight, low-energy or zero-energy building and constitute ca. $23 \%$ of all PURs [16]. Developing a porous polyurethane matrix with low cost waste polyurethane foam is an excellent way to decrease the price of rigid PUR foams which are the most effective thermal and phono insulation commercially available materials.

There is a growing awareness towards using materials with less social, economic and environmental impacts, in the construction and rehabilitation of buildings.

*email: ovidiu.nemes@imadd.utcluj.ro,horatiu.vermesan@imadd.utcluj.ro 
Polyurethane foam wastes can be used in producing composite materials. For instant, untreated and treated banana fiber with maleic anhydride and waste polyurethane foam were used in order to produce new composite materials with enhanced dielectric proprieties [17].

As a continuation of our scientific concerns [18-30] we present, in this paper, the possibility of recovering polyurethane foam waste in order to obtain new materials with sound absorbing properties. Polyurethane foam wastes were milled and mixed with polyurethane bicomponent foam as binder. The sound absorbing properties of rigid polyurethane foam with closed pores can be improved by adding different waste to their structure [21-13].

\section{Experimental part \\ Materials}

The development of new sound-absorbing materials by using waste as a raw material leads to reduce the use of the classical methods of waste recovery, which can be an advantage in reducing the amount of waste and at the same time, of the noise pollution.

The polyurethane foam waste (WPUF) was cut into parallelepiped shapes (Fig. 1 b)) to be ground using an MS-360 chopper. The shredded and ground polyurethane foam waste can be seen in figure $1 \mathrm{c}$ ). The size of the polyurethane foam waste is smaller than $5 \mathrm{~mm}$. The density of polyurethane foam waste is $0.0241 \mathrm{~g} / \mathrm{cm}^{3}$.

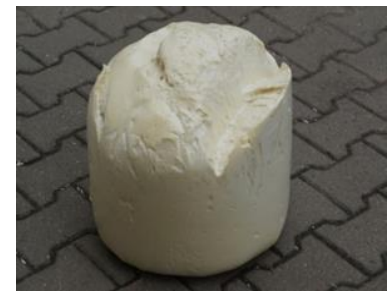

a)

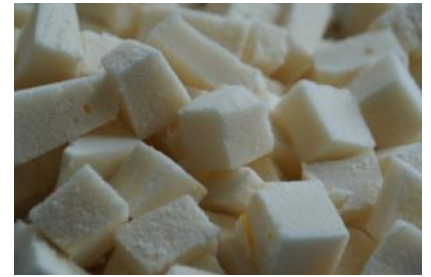

b)

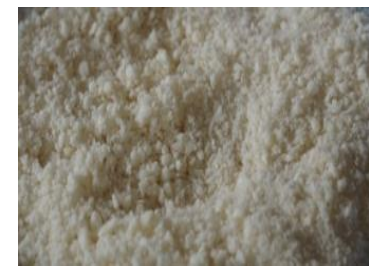

c)

Fig. 1 Polyurethane foam waste.

We have chosen to use rigid bicomponent polyurethane foam with closed pore flame retardant as a binder in obtaining composite materials with sound-absorbing properties, being one of the most used sound-absorbing materials. The foam used comes from the company SC BASF SRL. Rigid bicomponent polyurethane foam with closed pores has the following components: Component $\mathrm{A}$ is a formulated and flame retardant polyol, a component required to obtain a polyurethane foam. Component B is diphenylmethane-4,4'-di-isocyanante (MDI), one of the most widely used isocyanates in the production of polyurethane foams. Identifying element of this product IsoPMDI 92140.

Taking into account the size of the specimens necessary for the characterization of the sound absorbing materials, we have determined the size of the molds so that a plate with the following dimensions will result: length (L) $50 \mathrm{~cm}$, width (l) $65 \mathrm{~cm}$ and thickness (h) $10 \mathrm{~cm}$, so the thickness of the material has more values because the ability of a material to decrease the acoustic energy also depends on its thickness.

Polyol and isocyanate were mixed with polyurethane foam waste at determined weight ratios. The polyurethane foam wastes ground and mixed in proportion of $0,3,5,7$ and $12 \mathrm{wt} \%$. A mixer tool of up to $2000 \mathrm{rpm}$ was used in order to mix the composition for obtaining a homogeneous composition.

At the beginning of the study different weight percentage (wt $\%$ ) of waste materials in polyurethane foam were established.

Following the method above described 5 panels samples were obtained, made of waste polyurethane foams and rigid polyurethane foam as binder (Figure 2). The obtained plates have the size of $500 \times 650 \times 100 \mathrm{~mm}$, allowing an accurate study and a proper characterization of the new materials. The samples characteristics are shown in Table 1. The thickness was measured parallel along the foam rise direction. The samples had a thickness of $100 \mathrm{~mm}$.
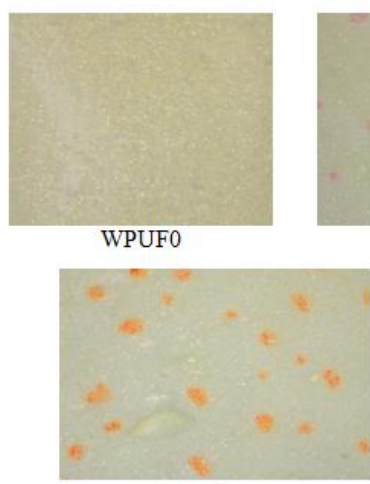

WPUF7

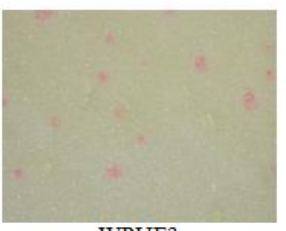

WPUF3
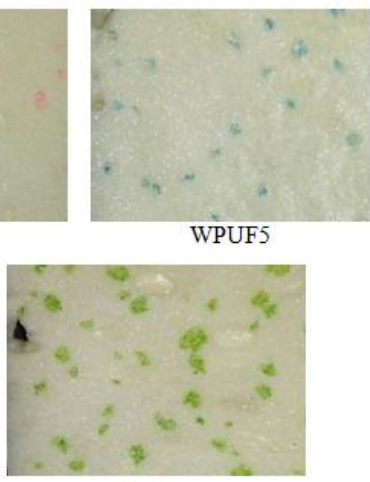

WPUF12

Fig. 2. Materials made from waste polyurethane foam and rigid polyurethane foam with closed pores 
For studying the possibility of incorporating polyurethane foam waste, came from decorative panels technology, another plate from $100 \%$ binder (rigid polyurethane foam) was made. In this way, the influence of the filling material (polyurethane foam waste), on the physical, mechanical, thermal and acoustic properties of the polyurethane foam can be studied compared with rigid polyurethane foam.

Table 1

SAMPLE PREPARATION

\begin{tabular}{|c|c|c|c|}
\hline Code & $\begin{array}{c}\text { Waste polyurethane foam } \\
{[\mathbf{w t} \%]}\end{array}$ & $\begin{array}{c}\text { Rigid polyurethane foam } \\
{[\mathbf{w t} \%]}\end{array}$ & $\begin{array}{c}\text { Apparent density } \\
{\left[\mathbf{g} / \mathbf{c m}^{\mathbf{3}}\right]}\end{array}$ \\
\hline WPUF0 & 0 & 100 & 0.314 \\
\hline WPUF3 & 3 & 97 & 0.321 \\
\hline WPUF5 & 5 & 95 & 0.350 \\
\hline WPUF7 & 7 & 93 & 0.373 \\
\hline WPUF12 & 12 & 88 & 0.473 \\
\hline
\end{tabular}

\section{Tensile strengths of composites}

For testing the influence of the percentage of polyurethane foam waste mixed into the two-component polyurethane foam matrix on the mechanical properties, compression tests were performed. These tests were performed using Intelli Jack $6 \mathrm{kN}$ testers. The results were recorded and processed using Instron Bluehill software. The compression behavior was determined according to BS EN 826: 2013 standard.

A compression force was applied on the axial direction perpendicular to the square surfaces of the specimen and the maximum stress supported by the specimen is calculated. When the maximum stress value corresponds to a relative deformation less than $10 \%$, the value is noted and attributed to compressive strength and the corresponding relative deformation is recorded. If the fracture does not occur before a relative $10 \%$ deformation is reached, the compression stress will be calculated at the relative deformation of $10 \%$, and the value will be recorded as compression stress at the relative deformation of $10 \%$.

Five cubic $(10 \mathrm{~cm}$ side) samples of each material were prepared for determine the compression behavior of the composite materials, according to the standard, as in figure 3.

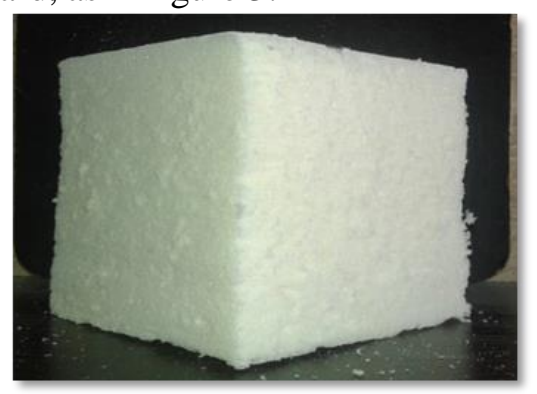

Fig. 3. Sample for determining the compression behavior of materials

\section{Thermal conductivity}

The thermal conductivity coefficient was determined according to SR EN 13165 with a thermal flow meter.

Thermal performance of materials obtained in this research was evaluated with FOX 200 Analyzer for measuring thermal conductivity. The maximum size of the sample that can be analyzed is $30 \times 30 \mathrm{~cm}$, and the thickness can be maximum $5 \mathrm{~cm}$. The temperature ranges were between $-20{ }^{\circ} \mathrm{C}$ and $-75{ }^{\circ} \mathrm{C}$ and accuracy of $\pm 1 \%$. The results are processed by the Wintherm $32 \mathrm{v} 2.30 .24$ software in tabular form, representing the differences in temperature (DT), the heat flow (HF), the thermal resistance (R) and the thermal conductivity $(\lambda)$.

\section{Sound absorption coefficient measurement}

The acoustic properties of the insulating composites used and the sound absorption coefficients were determined by the impedance tube method. The materials measurements were based on the two-microphone transfer-function method, according to ISO 10534-2 [04], which are for horizontally mounted orientation sensitive samples.

For accomplish the study a medium Brüel\&Kjaer Type 4206 A tube kit was used to measure various acoustic parameters for the frequency range of $100 \div 3200 \mathrm{~Hz}$. Medium impedance tube kit consisted of a $63.5 \mathrm{~mm}$ diameter tube and therefore tests were performed on circular samples with a diameter of $63.5 \mathrm{~mm}$ (Figure 4).

In order to determine the coefficient of acoustic absorption some samples containing only the polyurethane foam waste (WPUF100 coded sample) were prepared. 


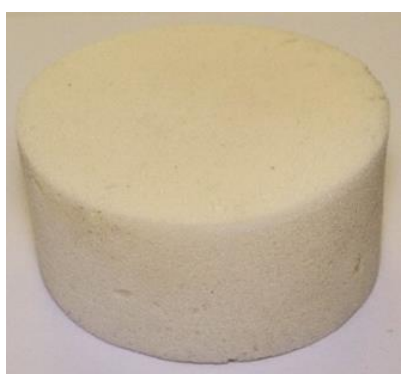

WPUF0

Fig. 4. Sample for sound absorption coefficient measurement

\section{Results and discussions}

The new obtained composite materials based on waste rigid polyurethane foam have been mechanically characterized (compression test) but also in terms of thermal and acoustic conductivity.

\section{Results for compression tests}

The compressive strength results obtained for the new five composite materials are shows in figure 5 . It can be observed that the two-component polyurethane foam material (without polyurethane foam waste) has the highest compressive strength. The addition of polyurethane foam wastes in to the two-component polyurethane foam matrices decreases the properties of compressive strength. However, all materials obtained as results of this research respect the minimum resistance imposed by standard for thermo- and phono- insulating materials. This conclude, that the polyurethane foam waste can be reused for sound absorbing panels, after prior shredding.

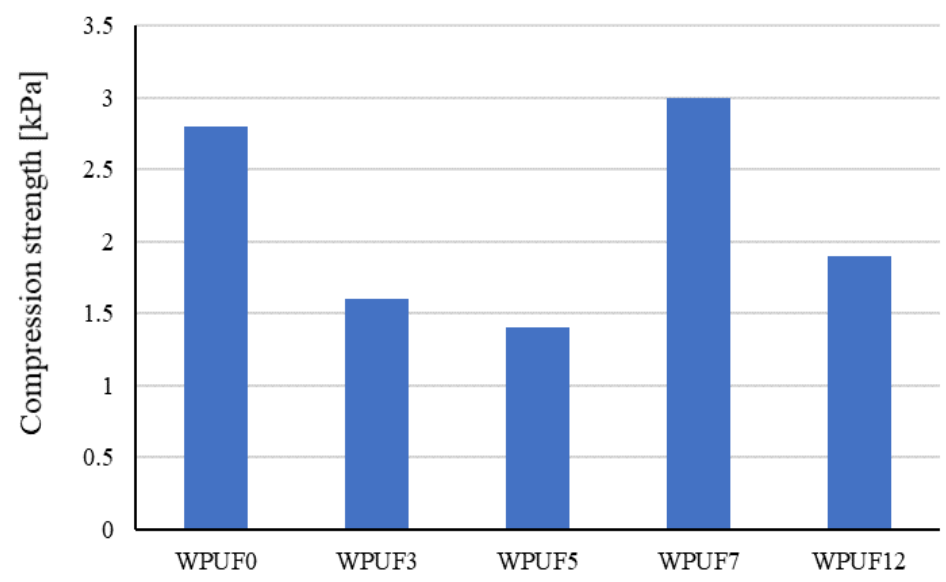

Fig. 5. Compressive strength of the studied samples

The interface between polyurethane foam wastes and the polyurethane bicomponent matrix affects the mechanical properties of polyurethane foam: poor interface properties result in a low efficiency of stress transfer from the matrix to polyurethane foam wastes under compression loading [25].

Figure 6 shows the variation of the elasticity modulus at compression depending on the percentage of polyurethane foam waste used to obtain the materials samples.

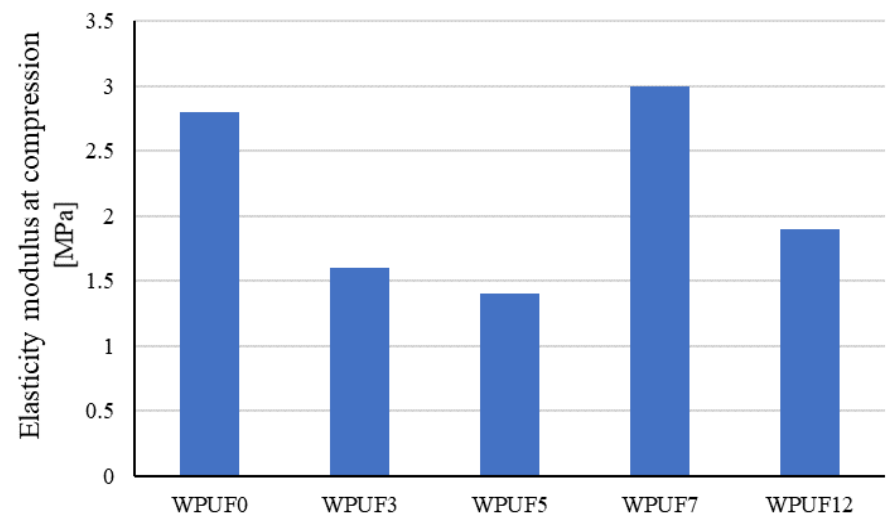

Fig. 6. Elasticity modulus at compression of obtained materials 
It can be seen that the WPUF7 sample has the best elasticity properties.

\section{Results for thermal conductivity tests}

Insulation is one of the most effective methods intended for reducing energy consumption in both heating and cooling of buildings. Selecting the right materials and determining the optimum insulation thickness in building insulation application is an important issue [26, 27].

Figure 7 shows the thermal conductivity of the sound-absorbing materials obtained from rigid two-component polyurethane foam and polyurethane foam waste.

The thermal conductivity tests show that the WPUF12 sample is a good thermal conductor, thus having the weakest thermal insulation properties. This is mainly due to the open porosity that occurs due to the higher percentage of polyurethane foam waste.

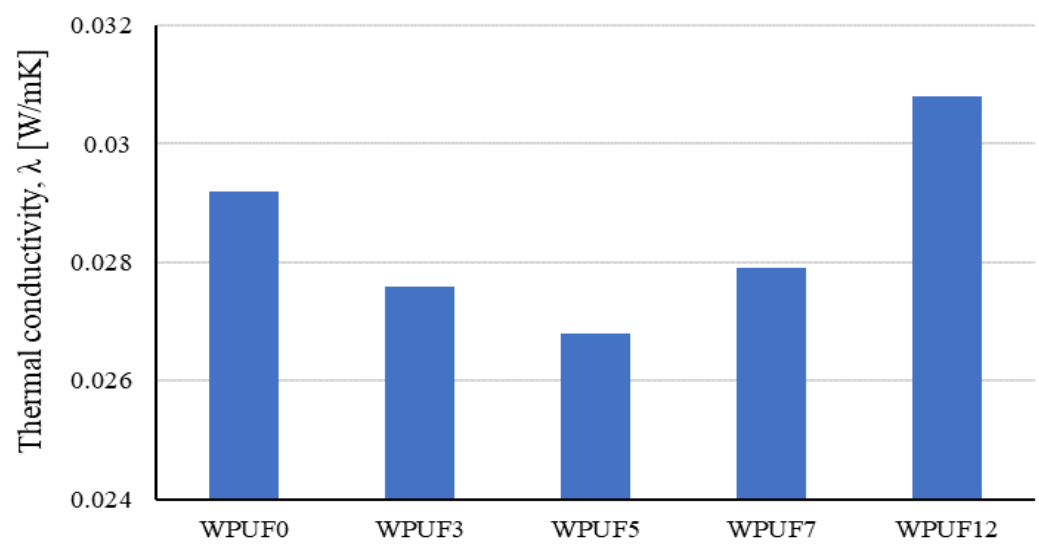

Fig. 7. Thermal conductivity for the obtained materials

From figure 7 it can be observed that the addition of 3\%, 5\% and 7\% of polyurethane foam waste in the twocomponent polyurethane foam matrix leads to the improvement of the thermal insulation properties of obtained materials.

\section{Results of acoustic tests}

The influence of the percentage of polyurethane foam waste on the acoustic absorption coefficient

The influence of the percentage of polyurethane foam waste, on the acoustic absorption coefficient is illustrated in figure 8 . The materials samples studied were obtained from $100 \%$ polyurethane foam waste, $12 \%, 7 \% ; 5 \% ; 3 \%$; and $0 \%$ and the difference was filled by the rigid two-component polyurethane foam matrix with closed pores.

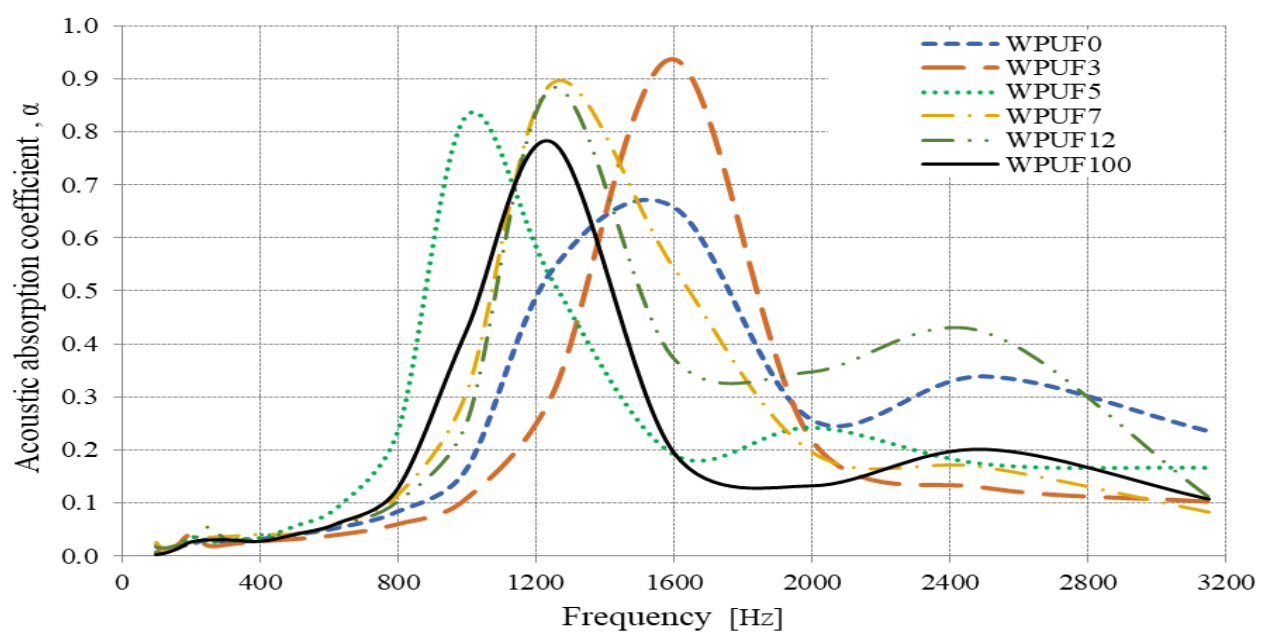

Fig. 8. Acoustic absorption coefficient variation with the percentage of polyurethane foam waste

From figure 8, it can be observed that for a percentage of 5\% polyurethane foam waste (WPUF5) the acoustic absorption coefficient improves in the frequency range $400-1000 \mathrm{~Hz}$ compared to the material obtained from $100 \%$ rigid polyurethane foam waste (WPUF100) and in Frequency range 400 - $1200 \mathrm{~Hz}$ compared to the material obtained of $100 \%$ rigid two-component polyurethane foam (WPUF0). 
Samples containing 3\% polyurethane foam waste (WPUF3) shows improved soundwave absorption properties in the $1400-1800 \mathrm{~Hz}$ frequency range compared to all other materials obtained in this study. For this samples the absorption coefficient reaches the maximum value of 0.94 at $1600 \mathrm{~Hz}$

We can conclude that WPUF12 material has the best sound absorption properties compared to the other materials, for it has the widest interval where the sound absorption coefficient reaches the value of 0.34 . This is due to the porosity formed and the increase of the size of the open pores, by the inclusion of polyurethane foam waste. At frequencies above $1800 \mathrm{~Hz}$ this material has the best sound absorption properties.

From variation of the acoustic absorption coefficient function of the percentage of polyurethane foam waste (figure 8), it can be observed that materials with a lower percentage of polyurethane foam waste have values of the absorption coefficient similar to that of the polyurethane foam. The samples with the highest percentage of polyurethane foam waste (WPUF7 and WPUF12) have the highest values of the noise absorption coefficient around the same frequencies.

\section{Comparisons with other materials}

The sound-absorbing properties of the new obtained materials compared with other materials already on the market (flexible polyurethane foam and glass wool) are presented in figure 9.

It can be observed that for materials with $12 \%$ polyurethane foam waste (WPUF12), there is an improvement in sound wave absorption properties in the frequency range $1000-1400 \mathrm{~Hz}$ compared to rigid and flexible polyurethane foams. The mineral wool has a very good acoustic absorption coefficient in the frequency range $500-700 \mathrm{~Hz}, 1100$ $3200 \mathrm{~Hz}$.

Compared to the other analyzed materials, flexible polyurethane foam has a better sound absorption coefficient in the frequency range $100-500 \mathrm{~Hz}$ and $800-1100 \mathrm{~Hz}$

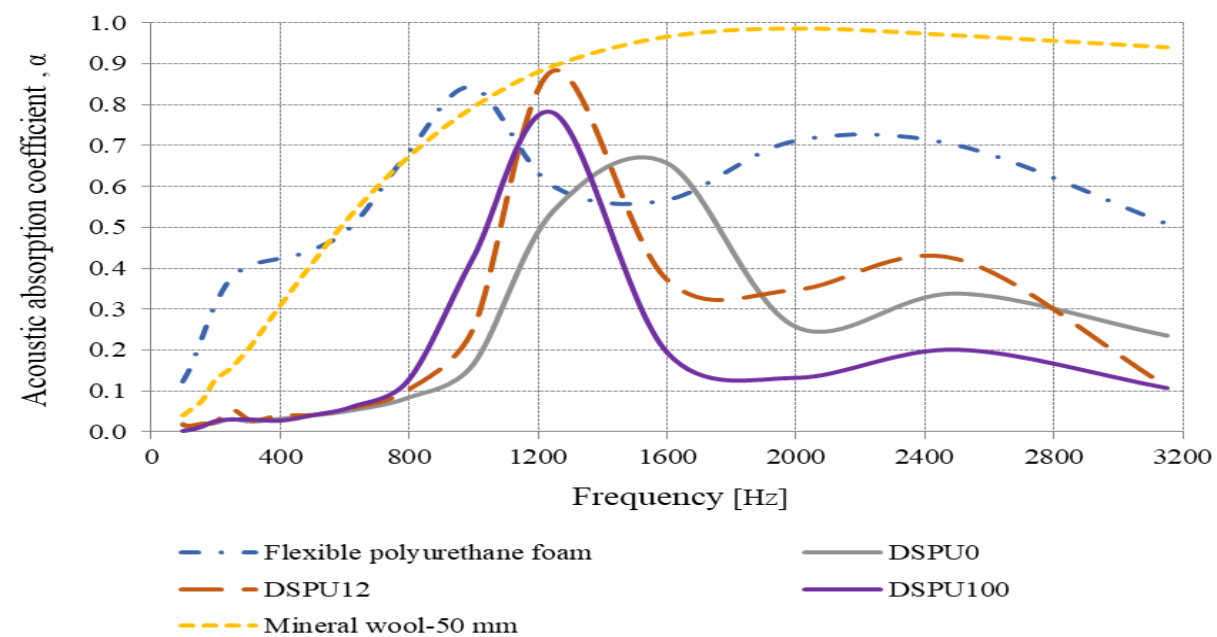

Fig. 9. Variation of acoustic absorption coefficient for DSPU0, DSPU12, DSPU100, flexible polyurethane foam and mineral wool

Acknowledgement: "The results presented in this paper were obtained in the framework of the GNaC 2018 ARUT grant "Innovative solutions for the acoustic comfort in open space offices", research Contract no. 3223/06.02.2019, with the financial support of the Technical University of Cluj-Napoca".

\section{Conclusions}

All the new obtained material exhibit sound absorption properties.

The density of the obtained materials increased with the increase of the percentage of polyurethane foam waste.

Addition of polyurethane foam waste to the two-component polyurethane foam matrix results in decrease of compressive strength properties. However, the materials comply with the minimum resistance required for soundproofing and thermo-insulating materials, resulting that the polyurethane foam waste could be re-introduced in the thirteen process, after prior shredding.

Addition of 3\%, 5\% and 7\% polyurethane foam waste into the two-component polyurethane foam matrix leads to improved thermal insulation properties of the studied materials.

Material containing 3\% polyurethane foam waste (DSPU3) shows an improvement of sound wave absorption properties in the $1400-1800 \mathrm{~Hz}$ frequency range compared to all other materials obtained in this study. For this material the absorption coefficient reaches the maximum value of 0.94 at $1600 \mathrm{~Hz}$

The DSPU12 material has the best acoustic absorption properties compared to the other materials, for it has the widest interval where the acoustic absorption coefficient reaches the value of 0.34 .

Increasing the percentage of polyurethane foam waste used in obtained materials increases the size and number of pores. 


\section{References}

1.MURRAY, A., SKENE, K., HAYNES, K., J. Bus. Ethics., 140, no.3, 2017, p.369.

2.STANČIN, H., RŮŽIČKOVÁ, J., MIKULČIĆ, H., RACLAVSKÁ, H., KUCBEL, M., WANG, X., DUIĆ, N., J. Environ. Manage., 243, 2019, p. 105.

3.AVCI, H., ÖZDEMIR, A. U., Celal. Bayar. Univ. J. Sci., 13, no. 4, p. 887.

4SORMUNEN, P., KÄRKI, T., J. Build. Eng., 24, 2019, p. 100742.

5.SIMÓN, D., BORREGUERO, A.M., DE LUCAS, A., RODRÍGUEZ, J.F., Waste Manag., 76, 2018, p. 147.

6.TERAKADO, O., YANASE, H., HIRASAWA, M., J. Anal. Appl. Pyrol., 108, 2014, p. 130.

7.ZIA, K. M., BHATTI, H. N., BHATTI, I. A., Reactive and Functional Polymers, 67, 2007, p. 675.

8.GUO, X., ZHANG, W., WANG, L., HAOB, J., J. Anal. Appl. Pyrol., 120, 2016, p. 144.

9.GARRIDO, M.A., FONT, R., J. Anal. Appl. Pyrolysis, 113, 2015, p. 202.

10.EDO, M., ORTUÑO, N., PERSSON, P. E., CONESA, J. A., JANSSON, S., Chemosphere, 203, 2018, p. 506.

11.GARRIDO, M. A., FONT, R., CONESA, J. A., Waste Manag., 52, 2016, p. 138.

12.PUSKAS, A., CORBU, O., KOLLO, S.A., Modern Technologies For The 3rd Millennium (16th National Technical-Scientific Conference on Modern Technologies for the 3rd Millennium), 2017, p. 239.

13.VIZUREANU, P., PERJU, M.C., GALUSCA, D.G., NEJNERU, C., AGOP, M., Metalurgia International, vol. XV, no. 12, 2010 , p. 59-64.

14.NABIALEK, M., JEZ, B., European Journal of Materials Science and Engineering, 2, no. 1, 2017, p. 33.

15.DULSANG, N., KASEMSIRI, P., Mater. Des., 96, 2016, p.350.

16.JUNCO, C., RODRÍGUEZ, A., CALDERÓN, V., MUÑOZ-RUPÉREZ, C., GUTIÉRREZ-GONZÁLEZ, S., Constr. Build. Mater., 190, 2018, p. 373.

17.KURAŃSKA, M., PROCIAK, A., Nano Biotech Based Mater. Energy Build. Effic. Springer International Publishing, Cham, 2016 , p. 357. 18.EL-MELIGY, M. G., MOHAMED, S. H., MAHANI, R. M., Carbohyd. Polym., 80, 2010, p. 366.

19.TIUC, A.E., RUSU, T., NEMEŞ, O., Obtaining process sound absorbent composite material. Patent No. 129228 B1, international classification C04B 26/26 (2006.01), 2015.

20.BORLEA (TIUC), A., RUSU, T., IONESCU, S., NEMEŞ, O., Rev. Rom. Mater., 42, no.4, 2012, p.405.

21.TIUC, A.E., NEMEŞ, O., VERMEŞAN, H., TOMA, A.C., Compos. Part B-Eng., 165, 2019, p. 120.

22.TIUC, A.E., MOGA, L., Romanian Journal of Acoustics and Vibration, 10, no.2, 2013, p. 77.

23.TIUC, A.E., VASILE, O., VERMESAN, H., Romanian Journal of Acoustics and Vibration, 12, no.2, 2015, p. 111

24.TIUC, A.E., VASILE, O., VERMESAN, H., ANDREI, P.M., Mat. Plast., 55, no.3, 2018, p. 419.

25.***, SR EN ISO 10534-2, Determination of sound absorption coefficient and acoustic impedance with the interferometer. Part 2. Transfer function method, 2002.

26.ZHANG, Z.X., ZHANG, J., LU, B.X., XIN, Z.X., KANG, C.K., KIM, J.K., Compos Part B-Eng., 43, no.2, 2012, p. 150.

27.RICCIARDI, P., BELLONI, E., COTANA, F., Appl. Energy, 134, 2014, p. 150.

Manuscript received: 26.11 .2019 